\title{
KSHV encoded miRNA single nucleotide polymorphisms identified in clinical samples can affect miRNA processing and level of expression
}

\author{
Vickie Marshall ${ }^{1 *}$, Soo-Jin Han², Eugene Barsov ${ }^{3}$, Octavio Quinones ${ }^{4}$, Alex Ray ${ }^{1}$, Robert Yarchoan ${ }^{5}$, David Ott ${ }^{3}$, \\ Rolf Renne ${ }^{2}$, Denise Whitby ${ }^{1}$ \\ From 13th International Conference on Malignancies in AIDS and Other Acquired Immunodeficiencies \\ (ICMAOI)
}

Bethesda, MD, USA. 7-8 November 2011

MiRNAs are a class of non-coding RNA molecules between 19-25 nucleotides in length that have been shown to be involved in many biological processes by post-transcriptionally regulating gene expression. Aberrant miRNA expression has recently been associated with disease including many human cancers. Kaposi's sarcoma associated herpesvirus (KSHV) encodes 12 miRNAs located within the latency associated region. We previously reported single nucleotide polymorphisms (SNP) in the sequence of KSHV encoded mature and pre-miRNAs from clinical samples [1]. An earlier report showed that a SNP in mir-K12-5 resulted in increased expression of the mature miRNA [2]. In the current study, we have analyzed three different classes of miRNA polymorphisms to determine if any affect mature miRNA processing and expression. The identified SNPs include single and multiple polymorphisms within the pre-miRNA transcript, single mutations within the terminal loop, and single sequence changes within the mature miRNA.

We used four complimentary approaches to detect differences in miRNA processing and expression resulting from sequence polymorphisms. Analysis of KSHV miRNA expression levels in PEL cell lines using custom ABI real time qPCR assays showed differential expression that correlates with sequence variation. Lentiviral vectors constructed to express wild type and variant pre-miRNAs were transduced into $293 \mathrm{~T}$ cells to make stably expressing cell lines. miRNA expression was assessed using custom ABI real time qPCR assays. Luciferase reporter

\footnotetext{
* Correspondence: marshallv1@mail.nih.gov

'Viral Oncology Section, AIDS and Cancer Virus Program, SAIC-Frederick, National Cancer Institute, National Institutes of Health, Frederick, MD, USA Full list of author information is available at the end of the article
}

assays were performed following transient transfections of each miRNA. In addition, in vitro maturation assays were performed to assess differences in Drosha/DGCR8 and Dicer cleavage between wild type and variant premiRNAs.

Our results show that polymorphisms within the premiRNA sequence can cause subtle expression differences as in the case of KSHV miR-K12-6 or more profound changes as observed in miR-K12-5. This is also the case with SNPs located within the terminal loop as some miRNAs exhibited no discernable change, miR-K12-7 and miR-K12-10, while others can cause a reduction in mature miRNA transcripts as noted in miR-K12-4. Mutations within the mature transcript appear to have the most potential to effect mature transcript processing and expression. The polymorphism within miR-K12-2 results in reduction of mature miRNA levels while the multiple changes in miR-K12-9 leads to complete loss of the mature transcript.

Our data clearly show that SNPs can affect premiRNA processing resulting in changes in mature miRNA expression levels. The biological significance of these phenotypic and genotypic variants merits further study.

\footnotetext{
Author details

'Viral Oncology Section, AIDS and Cancer Virus Program, SAIC-Frederick, National Cancer Institute, National Institutes of Health, Frederick, MD, USA. 2Department of Molecular Genetics and Microbiology, University of Florida, Gainesville, FL, USA. ${ }^{3}$ Retrovirus Assembly Section, AIDS and Cancer Virus Program, SAIC-Frederick, Frederick, MD, USA. ${ }^{4}$ Data Management Services, Inc., NCI-Frederick, Frederick, MD, USA. ${ }^{5} \mathrm{HIV}$ and AIDS Malignancy Branch, National Cancer Institute, National Institutes of Health, Bethesda, MD, USA.
} 


\section{References}

1. Marshall V, et al: Conservation of virally encoded microRNAs in Kaposi Sarcoma-Associated Herpesvirus in primary effusion lymphoma cells lines and in patients with Kaposi sarcoma or multicentric Castleman disease. JID 2007, 195(5):645-59.

2. Gottwein $E$, et al: A novel assay for viral microRNA function identifies a single nucleotide polymorphism that affects Drosha processing. I Virol 2006, 80(11):5321-6.

doi:10.1186/1750-9378-7-S1-P40

Cite this article as: Marshall et al.: KSHV encoded miRNA single nucleotide polymorphisms identified in clinical samples can affect miRNA processing and level of expression. Infectious Agents and Cancer 2012 7(Suppl 1):P40.

Submit your next manuscript to BioMed Central and take full advantage of:

- Convenient online submission

- Thorough peer review

- No space constraints or color figure charges

- Immediate publication on acceptance

- Inclusion in PubMed, CAS, Scopus and Google Scholar

- Research which is freely available for redistribution

Submit your manuscript at www.biomedcentral.com/submit 